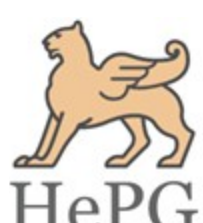

ISSN: 2348-1900

Plant Science Today

http://www.plantsciencetoday.online

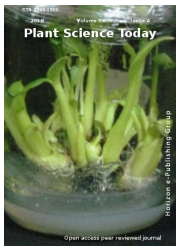

OPEN ACCESS

Research Article

\title{
Phytochemical screening, antibacterial and allelopathic effects of few invasive plants of Kerala
}

\author{
J M James, C U Geethumol, A Anilkumar, G Selvaraj \\ Department of Botany, Maharaja’s College, Ernakulam, India
}

\section{Article history}

Received: 14 July 2018

Accepted: 07 October 2018

Published: 12 November 2018

\section{Editor}

Dr. Bhupinder Dhir

Department of Genetics,

University of Delhi South

Campus, New Delhi, India

\section{Publisher}

Horizon e-Publishing Group

\author{
*Correspondence \\ Jess Mary James \\ 凶jessmary.james@gmail.com
}

\begin{abstract}
Invasive species are often regarded as a threat to native flora. Many of them curtail the normal physiological functioning abilities of the native plants by growing over them, or by producing certain metabolites which control their growth potentials and seed germination abilities. The present study aims to find out the different bioactive compounds like alkaloids and terpenoids responsible for the vast spread of Eupatorium odoratum, Vernonia cinerea, Mikania micrantha, Tridax procumbens, Pilea microphylla and Cuscuta reflexa which are some of the major invasive plants of Kerala. Apart from these negative roles attributed to invasive plants, whether they possessed any beneficial roles was the prime concern of this study. Our study brings to light the allelopathic effects of invasive plants upon legume seeds. Different phytochemicals which are known to produce such effect were present in all these plants. Greatest allelopathic effects were exhibited by $C$. reflexa and E. odoratum. Against Escherichia coli bacteria, E. odoratum and M. micrantha showed highest zone of inhibition $(20 \mathrm{~mm}, 15 \mathrm{~mm})$ while against Proteus vulgaris bacteria, C. reflexa, M. micrantha and T. procumbens produced inhibition zones of $21 \mathrm{~mm}, 15 \mathrm{~mm}$ and $12 \mathrm{~mm}$. Against Pseudomonas aeruginosa bacteria, $C$. reflexa, $M$. micrantha and $E$. odoratum produced inhibition zones of $16 \mathrm{~mm}, 13 \mathrm{~mm}$ and $12 \mathrm{~mm}$. Alcoholic extract of $V$. cinerea showed comparatively high inhibition against Staphylococcus aureus bacteria $(10 \mathrm{~mm})$. V. cinerea showed inhibitiory effects against $E$. coli, $S$. aureus and $P$. vulgaris $(11 \mathrm{~mm}, 10 \mathrm{~mm}$ and $9 \mathrm{~mm})$. Similarly, $P$. microphylla showed inhibition only against $P$. vulgaris and $P$. aeruginosa $(10 \mathrm{~mm}$ and $8 \mathrm{~mm})$.
\end{abstract}

\section{Keywords}

Invasive plants; allelopathy; phytochemicals; antibacterial; inhibition zone

\section{Citation}

James J M, Geethumol C U, Anilkumar A, Selvaraj G. Phytochemical screening, antibacterial and allelopathic effects of few invasive plants of Kerala. Plant Science Today 2018;5(4):175181. https://dx.doi.org/10.14719/pst.2018.5.4.408

Copyright: () James et al. (2018). This is an open-access article distributed under the terms of the Creative Co mmons Attribution License, which permits unrestricted use, distribution, and reproduction in any medium, provided the original author and source are credited (https://creativeco mmons.org/licenses/by/4.0/).

Indexing: Plant Science Today is covered by Scopus, CAS, AGRIS, CABI, Google Scholar, etc. Full list at http://www.plantsciencetoday.online

\section{Introduction}

Biodiversity refers to the variety of living organisms. It is the distribution, number, variety and variability of living organisms over time.
Habitat loss, introduced species, population growth, pollution and over consumption are regarded as the key reasons for loss of biodiversity. After habitat loss, invasive species are considered to be 
the second largest threat to biodiversity. An invasive species is a plant, or an animal species that is not found in its native place and has a tendency to spread to a new area or location and affects the native plants/animals living in that environment. Common features of invasive exotics include their ability to reproduce both asexually and sexually, fast growth, rapid rate of reproduction, high dispersal ability, tolerance against a wide range of environmental conditions and the ability to adapt or modify themselves in order to suit to the newly inhabited area. Invasive species can compete with natives for food, water, mineral nutrients and space. They often reduce light availability, moisture content, nutrient sources, and space available to native species. Some invasive plants produce secondary metabolites that inhibit the growth and development of native plants.

An introduced species turned to an invasive species by outcompeting the native species for resources such as nutrients, light, physical space, water or food thereby establishing a colony of their own by gradually replacing the existing species. Invasive species sometimes coexist with native species by adapting to the environment much rapidly and increasing in number and thereby modify the environment for their suitability. Invasive plants are more likely to have potent secondary metabolites which have been reported to have multiple activities like antiherbivory, antifungal, antimicrobial and allelopathic effects which may provide the plants with several advantages in their new environments (1). The presence of different chemical compounds in invasive plants gave super powers to them (2).

This study of few selected invasive plants like Eupatorium odoratum, Mikania micrantha, Vernonia cinerea, Pilea microphylla, Tridax procumbens and Cuscuta reflexa aims to find out the comparative phytochemical analysis, allelopathic effects and antimicrobial abilities, if any, for these groups of plants.

\section{Materials and methods}

\section{Preparation of extract}

Healthy plant specimens of Eupatorium odoratum, Mikania micrantha, Tridax procumbens, Vernonia cinerea, Pilea microphylla and Cuscuta reflexa were collected from Maharaja's College campus. The collected plant materials were washed under running tap water, shade dried, powdered and then stored in airtight containers. For phytochemical analysis, $10 \mathrm{~g}$ powder from each of the whole plant samples were weighed accurately and separately extracted in $50 \mathrm{ml}$ alcohol, acetone, chloroform and centrifuged. The supernatant was collected and kept in refrigerator till further use.

\section{Phytochemical analysis}

Alcohol, acetone and chloroform extracts of $E$. odoratum, $M$. micrantha, $T$. procumbens, $V$. cinerea, $P$. microphylla and $C$. reflexa were used for phytochemical studies as per standard procedures (3).

\section{Antimicrobial Assay}

Preparation of culture medium: $28 \mathrm{~g}$ of nutrient agar was weighed and transferred into beaker containing $1 \mathrm{~L}$ distilled water. Gently heated the contents to dissolve the medium and covered the mouth of the beaker with aluminium foil. Petriplates and nutrient agar containing beaker was placed in autoclave and sterilized. Further operations were done in laminar air flow chamber. The sterilized agar medium was poured into petridishes and allowed to solidify at room temperature and kept in an incubator in inverted position for $24 \mathrm{~h}$.

Four strains of bacteria available at Maharaja's College Botany lab were used for the study. The bacterial strains selected for study were Escherichia coli, Pseudomonas aeruginosa, Proteus vulgaris and Staphylococcus aureus. S. aureus is gram positive and the rest were gram negative.

The experiment was done in a laminar air flow chamber. The bacterial culture in nutrient broth was swabbed using buds over the solidified agar medium. A cork borer was used to prepare well in the medium. The medium was kept in the incubator for 2 to $3 \mathrm{~h}$. Extracts of the plants ( $1 \mathrm{~g}$ in $20 \mathrm{ml}$ acetone, alcohol and chloroform) of 5\% concentration were filled in the wells prepared. Ampicillin $(0.2 \mathrm{~g}$ in $100 \mathrm{ml}$ ) was kept as the positive control and the solvent in which the plant extracts were prepared (alcohol, acetone and chloroform) were taken as the negative control respectively. The petriplates were then inverted and kept in the incubator at $37^{\circ} \mathrm{C}$ for $24 \mathrm{~h}$ for the optimum growth of the organisms. After the stipulated period of time, petriplates were taken out, zone of inhibition was recorded using scale.

\section{Allellopathic study}

For the allelopathic studies, fresh leaves of $E$. odoratum, $M$. micrantha, $V$. cinerea, $T$. procumbens, $P$. microphylla and $C$. reflexa were collected and washed well under running tap water. All the extracts were prepared using distilled water in $1 \%$ concentration. The prepared extracts were filtered and kept in marked bottles for further use. Petridishes were washed properly in tap water and kept in hot air oven for complete drying. Petridishes were labeled and to each of them, fresh absorbent cotton was kept and extract was poured into each of them. Twenty five seeds each in two petridishes (duplicate) of the selected legume variety was placed as control (pure distilled water without any of the plant extracts), and also in different solvent extracts of the selected plants under study. Rate of germination 
were recorded at every 24, 48 and 72 hours after treatment and photographs were taken using camera. The seeds were considered as germinated when the radicle emerged and the germination percentage was calculated using the formula:

Germination Number of seeds germinated x 100

Percentage $=\quad$ Total number of seeds sown.

\section{Results}

\section{Phytochemical Analysis}

Preliminary phytochemical analysis of the whole plant extract of E. odoratum revealed all the major phytoconstituents like alkaloids, terpenoids, protein, phytosterols, saponins, flavonoids, phenol and tannins (Supplementary Table 1). Both alcoholic and acetonic extracts of $E$. odoratum showed more or less similar results and chloroform was not at all effective in extraction of phytocompounds. In the case of $V$. cinerea, phytoconstituents were comparatively more in alcoholic extracts (Supplementary Table 2). Only alkaloids, terpenoids and tannins were consistently present in different solvent extracts of $V$. cinerea. Alcoholic extract of $M$. micrantha revealed comparatively higher number of phytoconstituents than both acetonic and chloroform extracts (Supplementary Table 3) and the phytochemicals were saponins, flavonoids, phenols and tannins. In case of $T$. procumbens, alkaloids, terpenoids and phytosterols were present in all the three solvents selected for extraction. Saponins were present only in alcohol extract of $T$. procumbens (Supplementary Table 4). Phytochemical studies of $P$. microphylla revealed the presence of terpenoids and phytosterols in all the three solvents selected for study, while saponins, flavonoids and protein were present only in alcoholic extract (Supplementary Table 5). C. reflexa revealed the presence of phytosterols in all the three solvents and flavonoids and tannins were present in both alcoholic and acetonic extracts (Supplementary Table 6). Terpenoids, proteins, saponins and phenols were present in alcoholic extract only.

\section{Antibacterial studies}

Antibacterial studies of whole plant extracts yielded interesting results. Acetonic plant extracts against $E$. coli, E. odoratum showed the highest zone of inhibition $(20 \mathrm{~mm})$ followed by $T$. procumbens $(12 \mathrm{~mm}), V$. cinerea (11 $\mathrm{mm}), P$. microphylla and $M$. micrantha (10 $\mathrm{mm})$ (Supplementary Fig. 2-B). The positive control (antibiotic) obtained $22 \mathrm{~mm}$ inhibition zone and negative control (acetone) obtained $12 \mathrm{~mm}$. $C$. reflexa extract showed no inhibition at all against $E$. coli. Acetonic extracts against $P$. vulgaris showed maximum inhibition by $M$. micrantha (15 $\mathrm{mm}$ ) followed by $T$. procumbens $(12 \mathrm{~mm})$ (Supplementary Fig. 2-A), P. microphylla (11 mm),
$V$. cinerea $(9 \mathrm{~mm})$ and $C$. reflexa $(7 \mathrm{~mm})$. The positive control obtained $15 \mathrm{~mm}$ inhibition zone and negative control obtained $10 \mathrm{~mm}$. Acetonic extracts against $P$. aeruginosa showed maximum inhibition by $M$. micrantha $(13 \mathrm{~mm})$ followed by $P$. microphylla (8 mm) (Supplementary Fig. 2-C), T. procumbens $(7 \mathrm{~mm})$ and $V$. cinerea $(6 \mathrm{~mm})$. The positive control obtained $32 \mathrm{~mm}$ inhibition zone and negative control obtained $10 \mathrm{~mm}$. C. reflexa showed no rate of inhibition at all. Acetonic extracts against $S$. aureus was in the following order $V$. cinerea $(10 \mathrm{~mm})>C$. reflexa $(7 \mathrm{~mm})$ and $P$. microphylla $(6 \mathrm{~mm})$. The positive control obtained $20 \mathrm{~mm}$ inhibition zone and negative control obtained $6 \mathrm{~mm}$.

Alcoholic plant extracts against the different bacteria showed maximum inhibition by E. odoratum. No plant extracts in alcohol was effective against $E$. coli. Inhibition zone was obtained for $E$. odoratum plant extracts only against $P$. vulgaris and $S$. aureus $(7 \mathrm{~mm}$ and $5 \mathrm{~mm}$ ) (Supplementary Fig. 2-E). The positive control obtained $16 \mathrm{~mm}$ inhibition zone and $25 \mathrm{~mm}$ respectively against both $P$. vulgaris and $S$. aureus bacteria and negative control obtained no zones of inhibition in both cases. Only $T$. procumbens alcoholic extract was effective against $P$. aeruginosa bacteria $(9 \mathrm{~mm})$, here the positive control obtained $24 \mathrm{~mm}$ and negative control obtained $7 \mathrm{~mm}$ (Supplementary Fig. 2-F).

Chloroform extracts of $M$. micrantha, $T$. procumbens and $V$. cinerea were effective against E. coli $(15 \mathrm{~mm}, 5 \mathrm{~mm}$ and $3 \mathrm{~mm}$ ) (Supplementary Fig. 2-H), where the positive control was $(35 \mathrm{~mm})$ and negative control (chloroform) was $0 \mathrm{~mm}$. Chloroform extracts of $C$. reflexa, $M$. micrantha, $P$. microphylla, E. odoratum, T. procumbens and $V$. cinerea were effective against $P$. vulgaris $(21 \mathrm{~mm}$, $17 \mathrm{~mm}, 12 \mathrm{~mm}, 11 \mathrm{~mm}, 5 \mathrm{~cm}$ and $5 \mathrm{~mm}$ respectively) (Supplementary Fig. 2-I, J \& K), here the positive control was $19 \mathrm{~mm}$ and negative control was $9 \mathrm{~mm}$. Chloroform extracts of $C$. reflexa, E. odoratum, $V$. cinerea and $T$. procumbens were effective against $P$. aeruginosa $(16 \mathrm{~mm}, 12$ $\mathrm{mm}, 6 \mathrm{~mm}$, and $5 \mathrm{~mm}$ ) respectively (Supplementary Fig. 2-G \& K). Here the positive control was $26 \mathrm{~mm}$ and negative control was 9 $\mathrm{mm}$.

\section{Allellopathic studies}

Seed germination studies of selected legume revealed interesting features (Table 1). All the seeds of the selected legume germinated under control, i.e. in pure distilled water after $24 \mathrm{~h}$ of treatment. The seeds treated with fresh plant extracts of $C$. reflexa and $E$. odoratum did not germinate at all even after $72 \mathrm{~h}$. Seed germination in M. micrantha showed 24\% (12 seeds germinated out of 50 seeds selected for study) followed by $32 \%$ in $P$. microphylla (16 seeds germinated out of 50 seeds selected for study) $56 \%$ in $T$. procumbens (28 seeds germinated out of 50 seeds selected for 
Table 1. Seed germination studies of selected invasive plants

\begin{tabular}{lccc}
\hline Name of the plant & $\begin{array}{c}\text { Number of seeds germinated } \\
\text { out of 50 seeds }\end{array}$ & $\begin{array}{c}\text { Percentage of seed } \\
\text { germination }\end{array}$ & $\begin{array}{c}\text { Percentage of seed } \\
\text { germination (Control) }\end{array}$ \\
\hline Eupatorium odoratum & Nil & $0 \%$ & $100 \%$ \\
\hline Cuscuta reflexa & Nil & $0 \%$ & $100 \%$ \\
\hline Mikania micrantha & 12 & $24 \%$ & $100 \%$ \\
\hline Pilea microphylla & 16 & $32 \%$ & $100 \%$ \\
\hline Tridax procumbens & 28 & $56 \%$ & $100 \%$ \\
\hline Vernonia cinerea & 32 & $64 \%$ & $100 \%$ \\
\hline
\end{tabular}

study) and $64 \%$ in $V$. cinerea (32 seeds germinated out of 50 seeds selected for study). The allelopathic effect is considered to be highest for $C$. reflexa and $E$. odoratum followed by $M$. micrantha and $P$. microphylla. Allelopathic effect may be in reduced form for both $V$. cinerea and $T$. procumbens as above $50 \%$ seeds germinated in both of them.

\section{Discussion}

In the present study, the plants selected belonged to Asteraceae, Convoluvulaceae and Urtricaceae families. Asteraceae have the peculiarity of numerous seeds and pappus hairs that help them for long dispersal through wind and thus contributing to their invasive nature. From the study, M. micrantha, E. odoratum and C. reflexa grow over many native plants thereby reducing the availability of sunlight, curtailing the photosynthetic abilities and suspend the growth of host plants.

Phytochemical analysis of the different plant extracts revealed almost all the major phytoconstituents including alkaloids, phytosterols, diterpenes, flavonoids, saponins, tannins, phenols, etc. The present study on $E$. odoratum revealed the presence of alkaloids, flavonoids, phytosterols and diterpenes. Studies by Nayak et al. (4), revealed the presence of alkaloids in the phytochemical analysis of E. odoratum. Germination studies revealed the effects of certain phytochemicals which checked the normal process of germination. Seed germination could not even take place in the extracts of $E$. odoratum. According to Hoque et al. (5), different concentrations of $E$. odoratum leaf extracts caused significant inhibitory effects on germination, root and shoot elongation and development of lateral roots of receptor crops. Further it has been proposed that inhibitory effects were proportional to the concentration of the extracts and higher concentration has the stronger inhibitory effect (68). Acetonee extracts of $E$. odoratum were active against E.coli. From Supplementary Fig. 2-B it can be understood that against $E$. coli, E. odoratum showed the maximum zone of inhibition $(20 \mathrm{~mm})$. It was almost equal to positive control (antibiotic control) $(22 \mathrm{~mm})$ and higher than negative control (12 mm). Alcoholic extracts of E. odoratum showed inhibition against $S$. aureus $(5 \mathrm{~mm})$ (Supplementary Fig. 2-E) and P. vulgaris bacteria (7 mm) (Supplementary Fig. 2-E). Chloroform extracts of E. odoratum showed inhibition against P. vulgaris $(11 \mathrm{~mm})$ (Supplementary Fig. 2-K) and $P$. aeruginosa $(12 \mathrm{~mm})$ (Supplementary Fig. 2-K). Studies by Jai Sunder et al. (9), revealed that ethanol and methanol extracts of $E$. odoratum leaves showed maximum antibacterial activity against Salmonella pullorum, S. aureus, E. coli, Enterobacter aerogenes and Pseudomonas aeruginosa. Studies of Singh et al. (10), proved the antimicrobial activity of aqueous and methanolic leaf extract of $E$. odoratum against bacteria of clinical and non-clinical origin.

Analysis of $V$. cinerea whole plant extract revealed the presence of alkaloids, tannins, diterpenes, phytosterols and flavonoids. Haque et al. (11), conducted phytochemical screening of $V$. cinerea and showed the presence of steroids, triterpenoids and esters in the methanolic extract of stem bark and the leaves of the plant. Our study was in confirmation with the above said results. Allelopathic studies revealed $64 \%$ seed germination in $V$. cinerea. Studies of Purohit and Rosalin (12) revealed that the quantitative estimation of alkaloid contents of $V$. cinerea is $17.5 \%$ and they attribute allellopathic effects of the same may be due to this high concentration of alkaloids. Our studies also confirmed the presence of alkaloids in all the solvents selected for the study. Against $P$. vulgaris and E. coli, acetone extracts of $V$. cinerea showed inhibition zone of 9 $\mathrm{mm}$ and $11 \mathrm{~mm}$ respectively which was higher than negative control (6 mm) (Supplementary Fig. 2-D). Similarly, chloroform extracts of $V$. cinerea showed $10 \mathrm{~mm}$ zone of inhibition against $E$. coli and $5 \mathrm{~mm}$ against $P$. vulgaris. As per the studies of Gupta et al. (13), the benzene extract of $V$. cinerea showed a broad spectrum of antibacterial activity.

The phytochemical analysis of $M$. micrantha showed the presence of tannins, phenol, saponins and flavonoids in alcohol and tannins and diterpenes in acetone and carbohydrates and diterpenes in chloroform extracts. Phytochemical 
studies of the crude extracts of $M$. micrantha by Matawali et al. (14), had detected the presence of tannins, polyphenols, alkaloids, saponins and triterpenoids. Studies of $M$. scandens by Banerjee et al. (15), revealed the presence of alkaloids, flavonoids, tannins and steroids. In Mikania micrantha seed germination percentage was $24 \%$. Studies of Wong (16), pointed out that $M$. micrantha extracts can significantly reduce the dry weight and nitrogen content of tomato seedlings and legume cover crops. Acetone extracts of $M$. micrantha were active against $P$. vulgaris, $P$. aeruginosa and $E$. coli which obtained $15 \mathrm{~mm}, 13$ $\mathrm{mm}$ and $10 \mathrm{~mm}$ zone of inhibition (Supplementary Fig. 2-A). Alcoholic extracts could not bring about inhibition against microbes under study. Chloroform extracts of $M$. micrantha, showed zone of inhibition of $15 \mathrm{~mm}$ against $E$. coli (Supplementary Fig. 2-H). Against Proteus bacteria, M. micrantha obtained $15 \mathrm{~mm}$ zone of inhibition as can be understood from the Supplementary Fig. 2-I \& J). Some of the earlier studies reported that $M$. micrantha contained sesquiterpene lactones, diterpenes, flavonoids and phenolic compounds that mostly responsible for allelopathic response, antibacterial and anticancer activities (17-20).

The preliminary analysis of $T$. procumbens revealed the presence of alkaloids, diterpenes and phytosterols in all the solvents (alcohol, acetone, \& chloroform) selected for the study and the alcoholic extract revealed the presence of saponins also. The chloroform extract of leaves of $T$. procumbens by Sawant and Godghate (21) revealed the presence of steroids, saponins, alkaloids, coumarins, aminoacids, diterpenes, phenols and flavonoids. Our studies are in confirmation with the presence of above said components except coumarins, phenols and flavonoids. Allelopathic studies brings out $56 \%$ seed germination in Tridax, (28 seeds germinated out of 50 seeds selected for study). According to Manonmani et al. (22), aqueous leaf extracts of different concentrations of T. procumbens was found to have inhibitory effect on germination, root shoot elongation and fresh and dry weight of receptor plants and they concluded that the inhibitory effect was much more pronounced at higher concentrations. Acetone extracts of $T$. procumbens were active against E. coli, $P$. vulgaris and P. aeruginosa. From Supplementary Fig. 2-A \& B, it can be understood that against $E$. coli and $P$. vulgaris, T. procumbens showed $12 \mathrm{~mm}$ zone of inhibition and against $P$. aeruginosa, T. procumbens produced $7 \mathrm{~mm}$ zone of inhibition. Alcoholic extracts of Tridax was found to be active only against $P$. aeruginosa bacteria (9 $\mathrm{mm}$ ) (Supplementary Fig. 2-F). Chloroform extracts of $T$. procumbens showed zone of inhibition of $5 \mathrm{~mm}$ against $E$. coli (Supplementary Fig. 2-H). As per the studies of Bharathi et al. (23), the ethyl acetate extract of $T$. procumbens showed significant zone of inhibition against $S$. aureus, $S$. typhi and $B$. cereus than other two bacterial strains Klebsiella pneumonia and E. coli which showed lesser inhibition zones. Our studies showed comparatively higher inhibition against $E$. coli in acetone extracts.

Phytochemical analysis of P. microphylla whole plant showed the presence of phytosterols and diterpenes in all the solvents selected for study. Alcoholic extract brings out saponins, flavonoids, protein and tannin in addition to the above said phytoconstituents. Phytochemical studies by Chahardehi et al. (24), showed high concentrations of phenol and flavonoids in them. Allelopathic studies revealed $32 \%$ seed germination in Pilea, (16 seeds germinated out of 50 seeds selected for study). From the literature available, much conclusive support has not been obtained regarding the allelopathic properties of P. microphylla. Antibacterial activity was comparatively less in Pilea, both acetonic and chloroform extracts showed active inhibition only against $P$. vulgaris. Against $P$. aeruginosa, $P$. microphylla acetone extracts obtained maximum inhibition zone of $8 \mathrm{~mm}$ (Supplementary Fig. 2-C). Chloroform extracts of $P$. microphylla exhibited 10 $\mathrm{mm}$ inhibition against $P$. vulgaris where the positive control was $19 \mathrm{~mm}$ and negative control was $9 \mathrm{~mm}$ (Supplementary Fig. 2-I). According to Chahardehi et al. (24), crude extracts of $P$. microphylla inhibited growth of bacteria like $B$. cereus, $B$. subtilis, S. aureus and E. coli.

Phytochemical analysis of $C$. reflexa could bring out the presence of phytosterols in all the three solvents selected for study but flavonoids and tannins were present in acetone and alcohole extracts only. Protein, phenol, diterpenes and saponins were present only in alcoholic extract. As per the studies of Tapsya et al. (25), preliminary phytochemical screening revealed alkaloids, glycosides and flavonoids as the major groups of phytochemicals present in the extracts. The seeds treated with fresh plant extracts of $C$. reflexa did not germinate at all even after $72 \mathrm{~h}$. According to $\mathrm{Yu}$ et al. (26), there are allelochemicals in $C$. australis and many Cuscuta species which inhibited the growth and germination of seeds including weeds that can influence plant population density. Only chloroform extracts showed inhibitory activity against bacteria under study while both acetonic and alcoholic extracts were not effective. Chloroform extracts of $C$. reflexa brings about $21 \mathrm{~mm}$ inhibition zone against P. vulgaris, where the positive control was $19 \mathrm{~mm}$ and negative control was $9 \mathrm{~mm}$ (Supplementary Fig. 2-K). Here $C$. reflexa got values higher than the positive control which can be considered as a good result. Against $P$. aeruginosa, C. reflexa got $16 \mathrm{~mm}$ against positive control of $26 \mathrm{~mm}$ and negative control of $9 \mathrm{~mm}$ (Supplementary Fig. 2-K). Studies using ethanolic whole plant extracts of $C$. reflexa exhibited highest bactericidal properties against $E$. coli, followed by $B$. cereus and S. aureus but was not effective against $S$. typhi regardless of extract concentration (27). Studies revealed that 
terpenoids and phytosterols help plants against biotic or abiotic stresses and they are treated as signal molecules to attract the insects of pollination (28). From the present study, it can be learned that these compounds which are found in all the invasive plants selected, may help the plants to survive and propagate better under stressed conditions.

In conclusion, it can be inferred that, against $E$. coli, $E$. odoratum acetone $(20 \mathrm{~mm})$ and M. micrantha chloroform (15 mm) extracts are the best ones for inhibition where as in case of $P$. vulgaris, $C$. reflexa chloroform extract $(21 \mathrm{~mm})$ produced high effects followed by M. micrantha chloroform (15 mm). Against $P$. aeruginosa, $C$. reflexa chloroform $(16 \mathrm{~mm})$ and $M$. micrantha acetone $(13 \mathrm{~mm})$ performed well. In the case of $S$. aureus, only acetone extracts of $V$. cinerea, $C$. reflexa, P. microphylla performed better $(10 \mathrm{~mm}, 7$ $\mathrm{mm}$ and $6 \mathrm{~mm}$ ). Alcoholic extract of E. odoratum extract could bring out $5 \mathrm{~mm}$ zone of inhibition against $S$. aureus bacteria.

\section{Conclusion}

The selected invasive plants possessed several secondary metabolites which may be responsible for their invasive nature. Another major fact was that many of these compounds possessed by them proved to be efficient bactericidal agents (alkaloids, flavonoids, phenols, phytosterols, diterpenes, tannins and saponins) which can be used for synthesizing valuable drugs against both gram positive and gram negative organisms. Eupatorium odoratum, Mikania micrantha and Cuscuta reflexa showed comparatively high antibacterial results against Escherichia coli, Proteus vulgaris and Pseudomonas aeruginosa. Many of these secondary metabolites like alkaloids, saponins flavonoids etc which possessed strong antimicrobial, anti-infla mmatory, antitumor, antispasmodic and other such medicinal properties which can be utilized by thorough scientific investigation and isolation of individual compounds in them. This may help in the formulation of many wonder drugs for combating several harmful/ resistant microbes, disorders, etc. for the future generations to come.

\section{Acknowledgement}

The authors greatly acknowledge KSCSTE (Kerala State Council for Science, Technology and Environment) for the financial aid given for carrying out the work.

\section{Conflict of interest}

The authors have no conflict of interest.

\section{Authors' contribution}

GCU, AA and SG collected the specimens for study, conducted experiments and documented the data. JMJ designed and supported the experiments, supervised throughout the process and written up the whole manuscript.

\section{References}

1. Cappuccino N, Arnason JT. Novel chemistry of invasive exotic plants. Bio Lett. 2006;2(2):189-93. https://doi.org/ 10.1098/rsbl.2005.0433

2. Yu H, Liu J, He WM, Miao SL, Dong M. Restraints on Mikania micrantha by Cuscuta campestris facilitates restoration of the disturbed ecosystems. Biodiversity Journal 2009; 10(2-3):72-78. https://doi.org/10.1080/14888386.2009.9712847

3. Harborne JB. Textbook of Phytochemical Methods: A Guide to Modern Techniques of Plant Analysis. 5th ed. London: Chapman and Hall Ltd; 1998.

4. Nayak BS, Mishra D, Pradhan BS, Upadhaya D, Ellaiah P, Ramakrishna S. Phytochemical Investigation and Screening of Antibacterial Activity of Extracts from Leaves of Eupatorium odoratum. Linn Asian J Chem Pharm Sci. 2012; 24(5):2036-38.

5. Hoque AT, Ahmed RO, Uddin MB, Hossain MK. Allelopathic effects of different concentration of water extract of Eupatorium odoratum leaf on germination and growth behavior of six agricultural crops. Online J Biol Sci. 2003;3(8):741-50. https://doi.org/10.3923/jbs.2003.741.750

6. Ballester A, Vieitez AM, Vieitez E. Allelopathic potential of Erica vagans, Calluna vulgaris, and Daboecia cantabrica. J. Chem. Ecol. 1982;8(5):851-7. https://doi.org/10.1007/BF00994785

7. Rai JP, Tripathi RS. Allelopathic effects of Eupatorium riparium on population regulation of two species of Galinsoga and soil microbes. Plant and soil. 1984 ;80(1):105-17. https://doi.org/10.1007/BF02232944

8. Elroy LR. Allelopathy: An overview. In: Waller GR, editor. Allelochemicals: role in agriculture and forestry. ACS Symposium series Vol.330. Washington DC: Amer. Chem. Soc. 1987;8-22. https://doi.org/10.1021/bk-1987-0330

9. Sunder J, Jeyakumar S, Kundu A, Kumar De A. Antimicrobial activities of Eupatorium odoratum leaves. Indian Vet. J. 2012; 89(1):24-25.

10. Singh BR, Agrawal R, Sinha DK, Vinodh OR, Vadhana P, Bhardwaj M, Dubey S, Singh S. Antimicrobial activity in aqueous and methanolic leaf extract of Eupatorium odoratum against Bacteria of Clinical and Nonclinical Origin. J. Adv. Clin. Pharmacol. 2015;2(2):50-9.

11. Haque MA, Hassan mm, Das A, Begum B, Ali MY, Morshed H. Phytochemical investigation of Vernonia cinerea (Family: Asteraceae). J. Appl. Pharm. Sci. 2012; 2(6):79-83. https://doi.org/10.7324/JAPS.2012.2617

12. Purohit P, Rosalin R. Distribution of Alkaloides and Allelopathism of selected weeds from a post harvest crop field. International Journal of Innovative Research in Science, Engineering and Technology. 2015; 4(3):1308-1313.

13. Gupta M, Mazumder UK, Manikandan L, Haldar PK, Bhattacharya S, Kandar CC. Antibacterial activity of Vernonia cinerea. Fitoterapia 2003;74(1-2):148-50. https://doi.org/10.1016/S0367-326X(02)00291-5 
14. Matawali A, Chin LP, Eng HS, Gansau JA. Antibacterial and phytochemical investigations of Mikania micrantha HBK (Asteraceae) from Sabah, Malaysia. Trans. Sci. Technol. 2016;3(1):224-50.

15. Banerjee S, Chanda A, Adhikari A, Das AK, Biswas S. Evaluation of phytochemical screening and anti infla mmatory activity of leaves and stem of Mikania scandens (1.) wild. Ann Med Health Sci Res. 2014;4(4):532-6. https://doi.org/10.4103/2141-9248.139302

16. Wong R. Evidence for the presence of growth inhibitory substances in Mikania cordata (Burm. f.) B.L. Robinson. J. Rubber Research Institute of Malaya. 1964; 18(5): 231-242.

17. Cuence MD, Bardon A, Catalan CA, Kokke WC. Sesquiterpene lactones from Mikania micrantha. J. Nat. Prod. 1988;51(3):625-6. https://doi.org/10.1021/np50057a040

18. Huang H, Wei X, Ye W, Zhang C. Allelopathic potential of sesquiterpene lactones and phenolic constituents from Mikania micrantha H.B.K. Biochem Syst Ecol. 2008; 36(11):867-871. https://doi.org/10.1016/j.bse.2008.09.004

19. Pérez-Amador MC, Munoz Ocotero V, Ibarra Balcazar R, Garcia Jimenez F. Phytochemical and pharmacological studies on Mikania micrantha H.B.K (Asteraceae). Phyton-Revista Internacional de Botanica Experimental. 2010; 1;79-77.

20. Chaturvedi D. Sesquiterpene lactones: structural diversity and their biological activities, In-Opportunity, Challanges and Scope of Natural Products in Medicinal Chemistry. Research Signpost, Trivandrum. 2011:313-34.

21. Sawant RS, Godghate AG. Preliminary phytochemical analysis of leaves of Tridax procumbens Linn. International Journal of Science, Environment and Technology 2013; 2(3):388-94.
22. Femina D, Lakshmipriya P, Subha S, Manonmani R. Allelopathic effects of weed (Tridax procumbens L.) extract on seed germination and seedling growth of some leguminous plants. International Research Journal of Pharmacy 2012; 3(6):90-95

23. Bharathi V, Varalakshmi B, Gomathi S, Shanmugapriya A, Karpaga T. Antibacterial activity of Tridax procumbens Linn. Int. J. Pharma Sci. Res. 2012;3(4):364-7.

24. Modarresi Chahardehi A, Ibrahim D, Fariza Sulaiman S. Antioxidant, antimicrobial activity and toxicity test of Pilea microphylla. Int. J. Microbiol. 2010;2010:1-6. https://doi.org/10.1155/2010/826830

25. Gautam T, Gautam SP, Keservani RK, Sharma AK. Phytochemical screening and wound healing potential of Cuscuta reflexa. J. Chin. Pharm. Sci. 2015, 24 (5), 292-302. https://doi.org/10.5246/jcps.2015.05.038

26. $\mathrm{Yu} \mathrm{H}$, Liu J, He WM, Miao SL, Dong M. Cuscuta australis restrains three exotic invasive plants and benefits native species. Biol Invasions. 2011;13(3):74756. https://doi.org/10.1007/s10530-010-9865-x

27. Manirujjaman M, Suchana S, Collet T, Nawshin LN, Chowdhury MA. Antimicrobial effects of ethanolic extracts from Cuscuta reflexa Roxb. (Convolvulaceae). International Journal of Pharmacognosy and Phytochemical Research. 2016;8(6):930-2.

28. Singh B, Sharma RA. Plant terpenes: defense responses, phylogenetic analysis, regulation and clinical applications. 3 Biotech. 2015;5(2):129-51. https://doi.org/10.1007/s13205-014-0220-2 